\section{PROCESSABILITY OF WC-CO POWDER MIXTURES USING SLM ADDITIVE TECHNOLOGY}

Department of Material Science and Technology, Faculty of Mechanical Engineering, University of West Bohemia,

Univerzitni 8, 301 00, Pilsen. Czech Republic

DOI: 10.17973/MMSJ.2019_06_2018115

e-mail: bricda@kmm.zcu.cz

This contribution presents the findings from an experimental study which explored the possibility of processing WC-Co-based powders using selective laser melting (SLM) additive technology. Two commercially available WC-Co powder mixtures were studied. One is intended for thermally sprayed coatings and the other for isostatic pressing applications. Both were analysed using optical and scanning electron microscopy and then processed in an additive manufacturing (AM) machine. Process parameters were proposed on the basis of a literature search and metallographic characterization of the mixtures. Metallography was also employed for examining the prototype specimens. The mixtures were found to differ in morphology, technological properties and phase composition, which was also manifested during their processing. The powder mixture for thermally sprayed coatings proved completely inadequate for AM due to undesirable grain morphologies and phase composition. The powder mixture for isostatic pressing was found to be more suitable. Nevertheless, all the builds were highly porous which had an adverse impact on the product properties.

KEYWORDS

SLM technology, WC-Co cemented carbides, powder mixture properties, internal defects, phase analysis

\section{INTRODUCTION}

Additive manufacturing (AM) has started to gain a foothold in various sectors of industry. In the healthcare sector it is used for making prostheses. Aircraft engine parts are made using AM with a view to reducing their complexity, the number of joints and spare parts, and thus simplifying their maintenance and manufacture. Most AM materials are single-phase polymers, non-ferrous metals and ferrous alloys. [Venuvinod 2004]; [Sames 2016]; [Gu 2015] Cemented carbides (CC) are not yet produced by SLM, however, CC manufacturers are considering AM applications, and this was the motivation for this study. The SLM process was employed for these experiments. It relies on depositing a powdered material layer by layer. Once deposited, each powder layer is melted by a continuous fibre laser in a protective atmosphere of argon, nitrogen or helium gas. The type of laser and the protective atmosphere influence the penetration depth of the laser beam and the amount of energy introduced. The energy should be sufficient to cause melting and fusion of the powder particles and melt the layers together. The energy which will be consumed in melting and sintering the powder into the final product is supplied at a rate dictated by the laser spot speed and size, the offset between the laser paths and the laser power. [Khairallah 2016]; [Kumar 2009] The speed (vs), the offset between paths (hs), the laser power (P) and powder layer thickness (Is) govern the energy density (Ev), which should be adjusted accurately to ensure that the powder layer is melted and that solid, pore-free products are obtained. This energy density Ev is expressed using equation 1 below. [Uhlmann 2018]

$E_{v}=\left(P /\left(I_{s} \cdot h_{s} \cdot v_{s}\right)\right)$

The impact of $\mathrm{Ev}$ on the mechanical properties and microstructure of the builds was investigated using two different WC-Co powder mixtures. Since these mixtures are not intended for SLM, their technological properties were tested first, including flowability, spreading behaviour and layer compactness. Furthermore, their phase composition and the geometric characteristics of the particles and structural and surface defects were examined using metallographic analysis. After the analysis, SLM processing was carried out in collaboration with Technical University of Liberec. The builds were examined using optical and scanning electron microscopes and their Vickers hardness was measured according to the HV1 scale.

\section{EXPERIMENTAL MATERIAL AND PARAMETERS}

At present, no WC-Co powder mixtures suitable for SLM are available. This experiment was carried out on two different mixtures intended for different industrial applications. The first bears the trade name SD251, and is ordinarily used for thermally sprayed coatings. Its designation in this study is " $\mathrm{A}$ ". The second, CTE50A, is used for press forming applications and its designation in this study is " $\mathrm{B}$ ". Their chemical compositions are rather similar (WC-Co), but differ in the levels of Co binder. Powder mixture B contains $25 \%$ Co, which is $50 \%$ more binder than mixture A. Metallographic analysis revealed additional differences which affect their processability by SLM.

The first difference is the particle shape, see figures 1,2 and 3. Important aspects for additive manufacturing include the shape of the powder particles, which should ideally be globular, and their surfaces preferably without evident defects, such as craters, cavities and satellites. The shapes of the particles and surface defects in them affect the powder's flowability. Flowability of the powder is also affected by the particles' surface roughness, size distribution, and also residual moisture. Therefore the powders were dried to a residual moisture level lower than $5 \%$ before starting the experiment. [Armstrong 2014] Flowability is manifested as the continuous and rapid flow of the particles onto the build platform of the AM machine. It determines the ability of the powder to form a uniform layer on the build platform. The graph in Fig. 3 shows that powder mixture $B$ contains a larger fraction of particles with a round profile than mixture $A$. It should therefore show better flowability than powder mixture $A$.

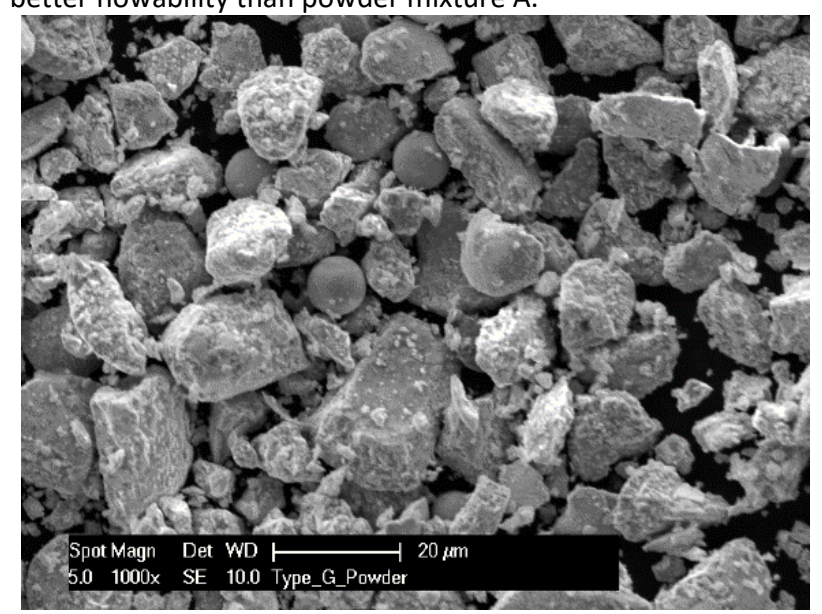

Figure 1. Shapes of particles in powder mixture A, magnification 1000x 


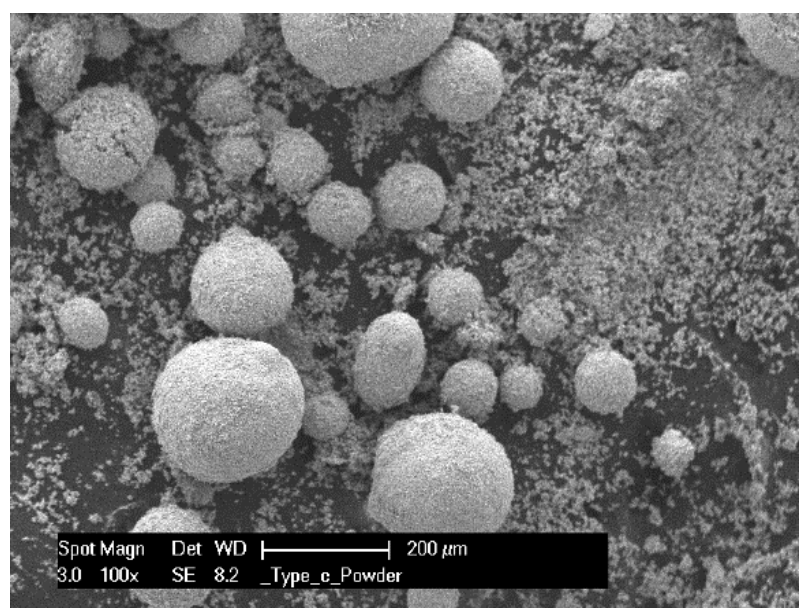

Figure 2. Shapes of particles in powder mixture B, magnification $100 x$

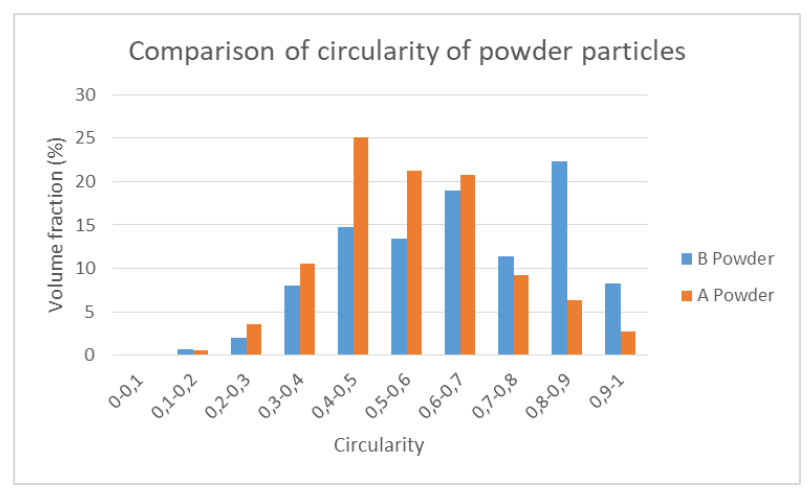

Figure 3. Circularity of particles in powder mixtures

Besides having an appropriate morphology, the particles should also have the right size distribution. The average size of the powder particles is about $30-45 \mu \mathrm{m}$ in most cases. It depends on the additive technology which is used. [Dawes 2015] Figures 1 and 2 and the graph in Fig. 4 suggest that both $A$ and $B$ mixtures contain such fine particles. In powder mixture $B$, these fine particles are in fact individual WC and Co grains whose clusters make up the spherical particles seen in Fig. 2. The grains are mutually attracted by Van der Waals forces. Some of the clusters therefore fall apart once they hit the build platform, as shown in figures 2 and 6 . In powder mixture A, the presence of fine particles is due to inadequate sieving. They stick to larger particles due to adhesive forces. Their size is given by the size factor of the powder particles and by their shape and roughness. In this case, it was possible to remove particles with sizes under $10 \mu \mathrm{m}$ by, for instance, elutriation using an appropriate fluid or by improved sieving. Besides the lower size limit, the particles should meet an upper limit as well, usually $70-100 \mu \mathrm{m}$, depending on the AM machine type. In this study, particles under $10 \mu \mathrm{m}$ were removed from powder mixture A by sieving with modified screens. However, the fine fraction was impossible to remove from powder mixture $B$ because it consisted of actual WC and Co grains, as explained above. Powder mixture $B$ was therefore used in its original condition.

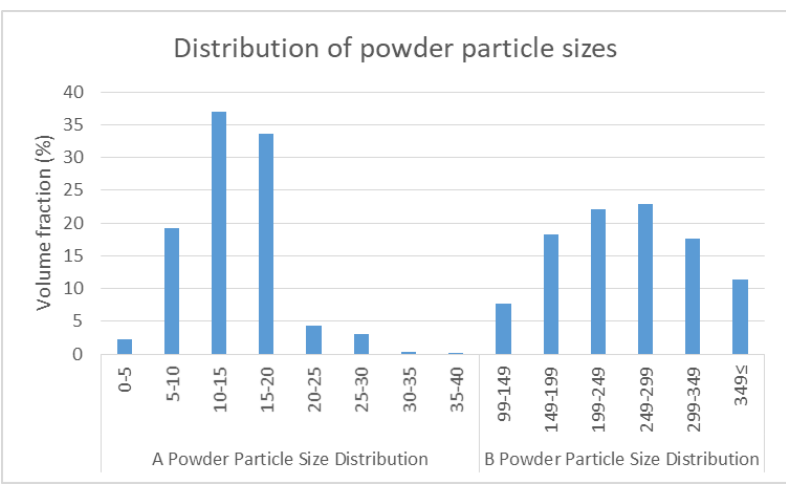

Figure 4. Distribution of particle sizes in WC-Co powder mixtures

The above analysis confirmed that in terms of particle shape and size distribution, the two powder mixtures are not entirely suitable for SLM processing. Although the shape and size of the powder particles were not ideal, the flowability and bulk density tests found that these properties are similar to those of steel powders currently used in additive technology. Powder A showed a higher bulk density than steel powder. The difference was that in the analysed powder there was an interruption of the flow of the powder. This was due to the high friction between the powder particles, but because of the high bulk density it was used for further experiments. For powder B, the flow of powder was fluid and therefore this type of powder was used for further experiments. Prior to printing from powder blends $A$ and $B$, a test was carried out to determine the powder flow and the integrity of the powder layer formed on the build platform of the additive device. After the experiment, the layer was evaluated using light and electron microscopy. The results of this test are shown below in figures 5 and 6 .

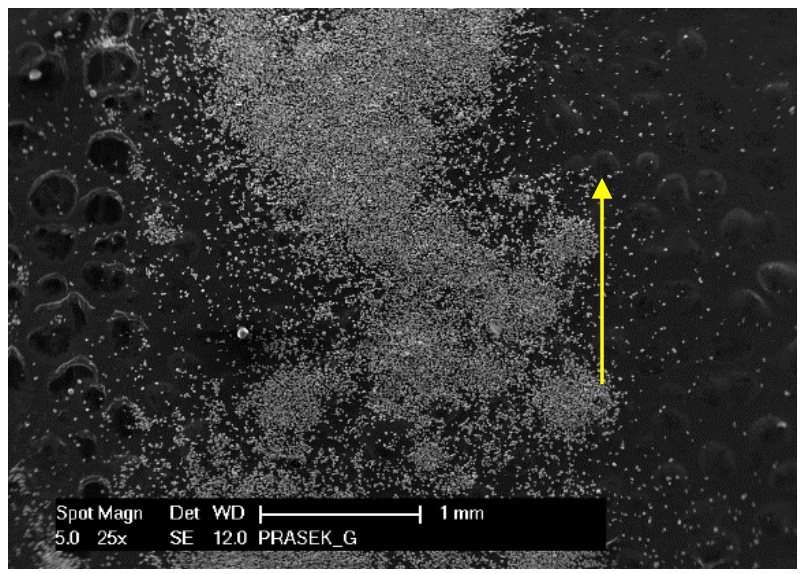

Figure 5. Powder layer continuity and surface coverage by particles of powder mixture A. The arrow indicates the direction of movement of the belt onto which powder was poured through an orifice 


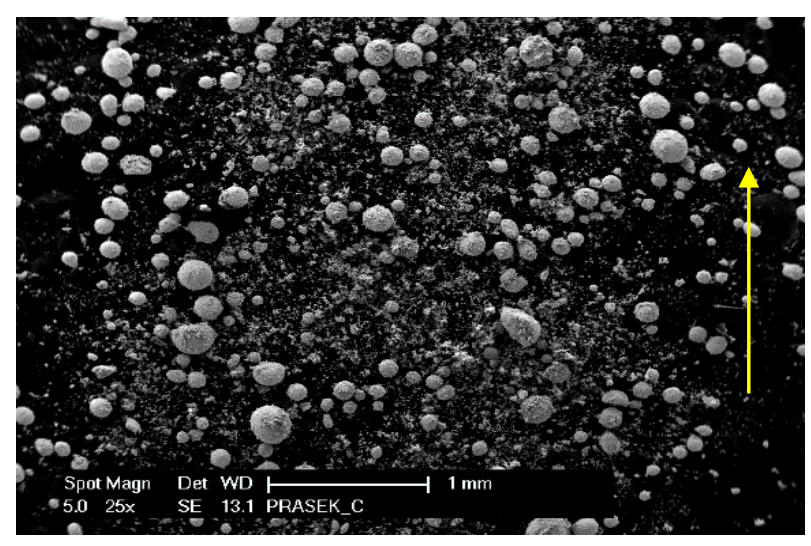

Figure 6. Powder layer continuity and surface coverage by particles of powder mixture $\mathrm{B}$. The arrow indicates the direction of movement of the belt onto which powder was poured through an orifice

Figures 5 and 6 show that powder mixture A forms a more continuous layer than the other mixture. This is because of its higher bulk density and more favourable spread of particle sizes than in powder mixture $B$. Based on known particle distribution, the feed rate to the build platform of the AM machine could be adjusted, preferably before the AM process. Figures 5 and 6 show that using this equipment, the behaviour of powder mixtures can be compared before the 3D printing process. The powder mixture which is better suited for SLM can be chosen by comparing the uniformity of the powder layers, spreading behaviour and layer compactness.

In addition to the shape, morphology and size distribution of the particles, the phase composition is also important for AM. Steel and non-ferrous metal powders contain single-phase particles with a uniform chemical composition. With a uniform phase composition, the energy needed for melting a particle is the same throughout its volume. Such particles become fully melted and fused together. However, each WC-Co powder mixture contains at least two phases: tungsten carbide and binder, which in this case is cobalt. Consequently, the energy required for melting varies with the location within the particle - and complete melting does not occur. Sintering then takes place in the presence of a solid phase, unlike in steel powders. Metallographic analysis also reveals a non-uniform phase distribution within the particles (see figures 7 and 8). $\eta$-phase was detected in powder mixture A. This is normally considered an undesirable constituent because it is brittle and impairs the mechanical properties of the cemented carbide. [Sarin 2014]

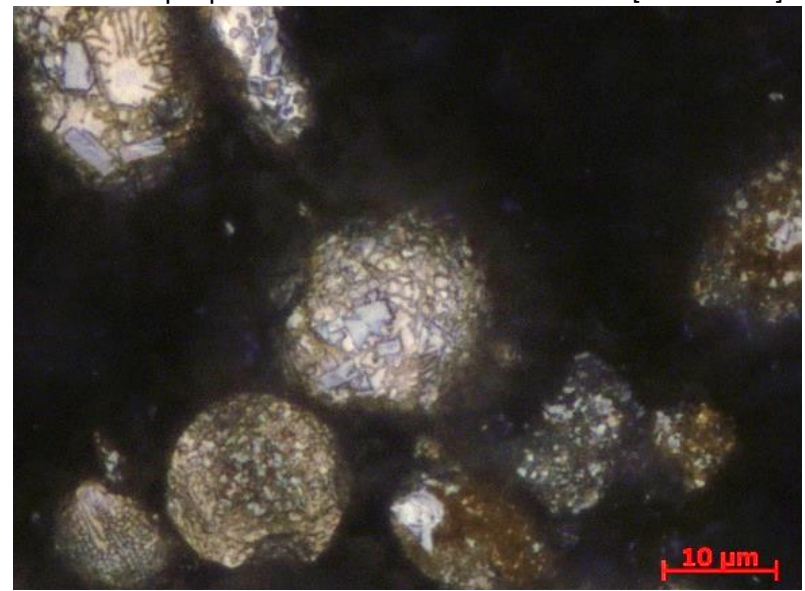

Figure 7. Microstructure of powder particles A, Murakami etch, magnification 1000x. The bright areas are the binder (cobalt), the orangebrown areas are $n$-phase, and the grey regions are tungsten carbide WC

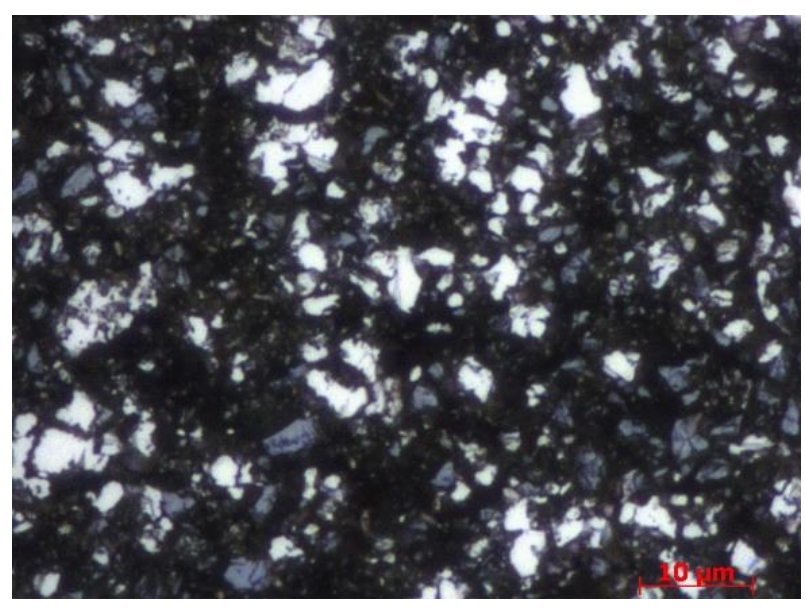

Figure 8. Microstructure of powder particles B, Murakami etch, magnification $1000 \times$. The bright areas are the binder (cobalt) and the dark and grey regions are tungsten carbide WC

The presence of $\eta$-phase was expected to make it difficult to process WC-Co powder using AM, and this was confirmed by the experiment.

Both powder mixtures were processed in SLM equipment in collaboration with Technical University of Liberec. The process parameters are given in Table 1 . Their values were based on findings from metallographic analysis, a literature search and on earlier experiments with WC-Co powder mixtures. [Kurzynowski 2012]; [Uhlmann 2018]; [Wang 2002]; [Domashenkov 2016]

\begin{tabular}{|l|l|l|l|}
\hline $\begin{array}{l}\text { Powder } \\
\text { type }\end{array}$ & Ev & $\begin{array}{l}\text { Inert } \\
\text { atmosphere }\end{array}$ & $\begin{array}{l}\text { Powder } \\
\text { layer } \\
\text { thickness } \\
(\mu \mathrm{m})\end{array}$ \\
\hline A & $50-550$ & Nitrogen & 40 \\
\hline B & $30-1000$ & Nitrogen/argon & 100 \\
\hline $\begin{array}{l}\text { Powder } \\
\text { type }\end{array}$ & $\begin{array}{l}\text { Angle between } \\
\text { laser paths in } \\
\text { consecutive } \\
\text { layers }(\mu \mathrm{m})\end{array}$ & $\begin{array}{l}\text { Offset between } \\
\text { laser paths }(\mu \mathrm{m})\end{array}$ & $\begin{array}{l}\text { Laser spot } \\
\text { size }(\mu \mathrm{m})\end{array}$ \\
\hline A & $90^{\circ}$ & 120 & 120 \\
\hline B & $90^{\circ}$ & 120 & 120 \\
\hline
\end{tabular}

Table 1. Process parameters used for WC-Co powder mixtures

\section{EXPERIMENTAL RESULTS AND DISCUSSION}

Using the parameters shown in Table 1, several series of builds were created to identify the impact of the process parameters, most notably the energy density $\mathrm{Ev}$, on specimen properties. In some cases, various structural defects, shown in Fig. 9, occurred during printing and after removal from the AM machine. 


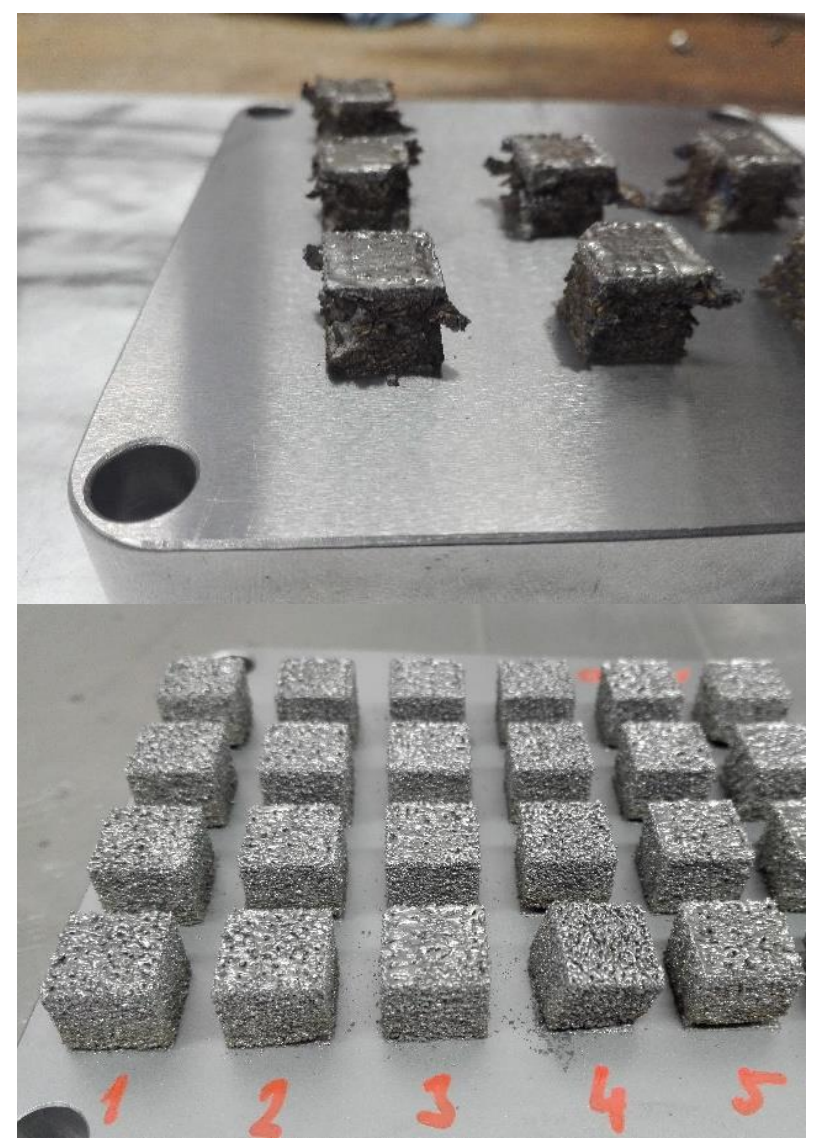

Figure 9. Prototype specimens after removal from the SLM machine and cleaning. Above: builds from powder mixture A. Below: builds from powder mixture $B$

As the figure shows, some builds separated from the build platform due to delamination and in others the edges broke away across the sintered layers. These defects were associated with residual stresses caused by temperature gradients. These gradients occurred because in this process the melt only forms for a fraction of a second and then solidifies immediately. In addition, structural changes took place during sintering, which caused volume changes that led to higher residual stresses. Besides delamination, the builds showed considerable porosity. The pores varied from being regularly spherical to irregular in shape. There were also cracks across the builds or at the line of fusion between layers, (see Fig. 10 and Fig. 11). The number and the aggregate volume of these defects determines the density of the build. Fig. 12 illustrates the relationship between energy density and build density.

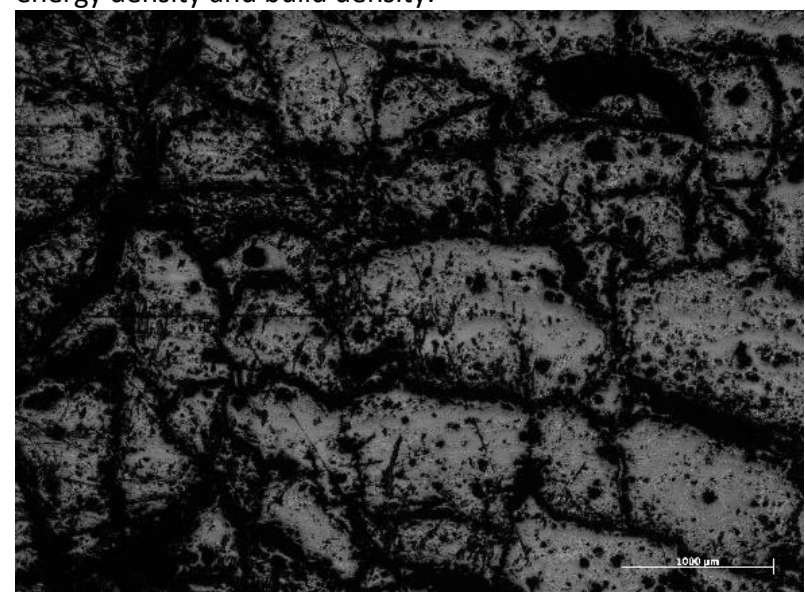

Figure 10. Micrograph of a sintered build from powder mixture A. In these specimens, the majority of defects were cracks, magnification $25 \times$.

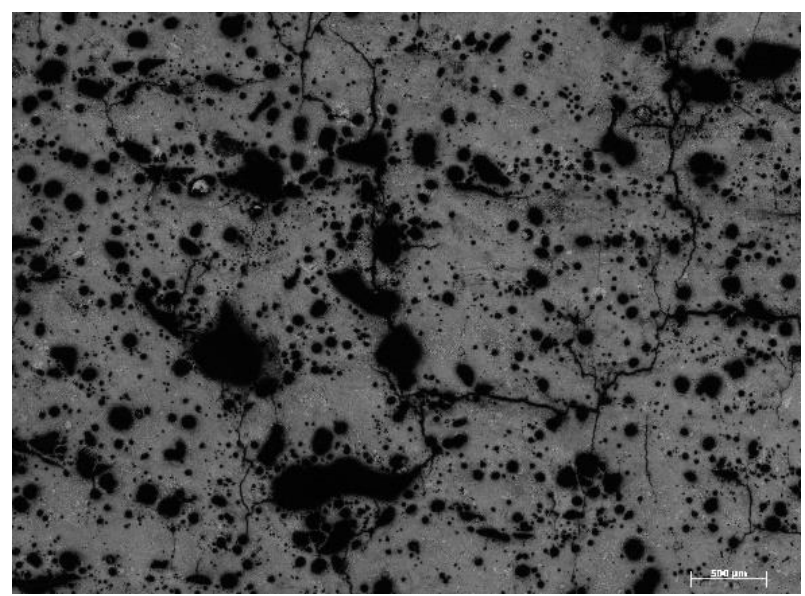

Figure 11. Micrograph of a sintered build from powder mixture B. In these specimens, the majority of defects were spherical closed pores, magnification $25 \times$

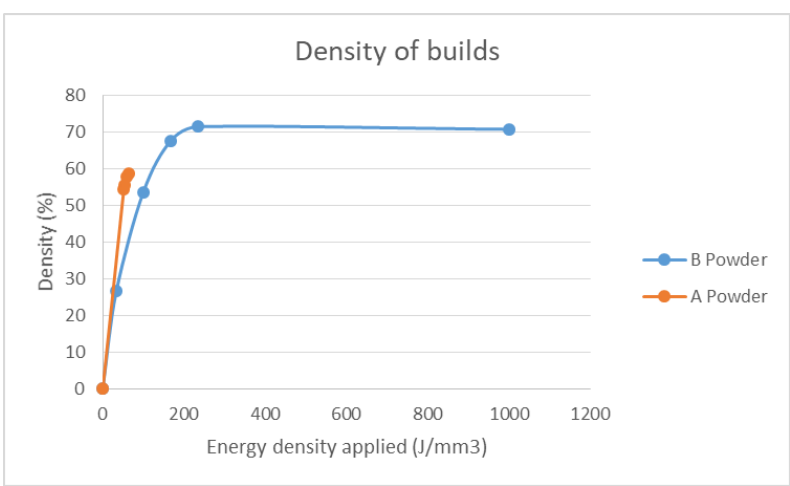

Figure 12. Build density vs. energy density $E_{v}$

At $E_{v}$ values higher than $100 \mathrm{~J} / \mathrm{mm}^{3}$, builds from powder mixture A separated from the build platform due to delamination while the first layers were being created. Processing of powder mixture A was therefore terminated early. Fig. 12 suggests that higher density in sintered specimens can be obtained by reducing the powder layer thickness. However, this proved impossible in powder mixture B due to the size of the particles, i.e. grains. In addition, this graph shows that beyond approx. $500 \mathrm{~J} / \mathrm{mm}^{3}$ the density of sintered builds decreases slightly. This is related to increased sublimation of powder particles at higher energy levels. During solidification, the gas becomes trapped while still expanding, and therefore exerts pressure on its surroundings. Consequently, round pores become stable and continue to grow in the builds.

The density of builds also varies with structural changes that take place during sintering. Micrographs of etched specimens are shown in Fig. 13 and Fig. 14. 


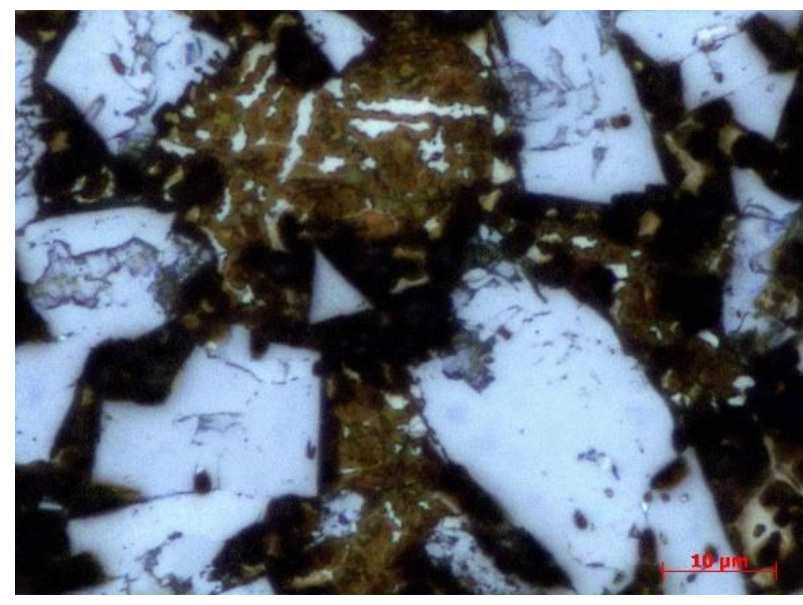

Figure 13. Micrograph of a sintered build from powder mixture A. White areas are cobalt, brown-orange areas are $\eta$-phase and the grey areas are tungsten carbide WC, magnification 1000×, Murakami etch

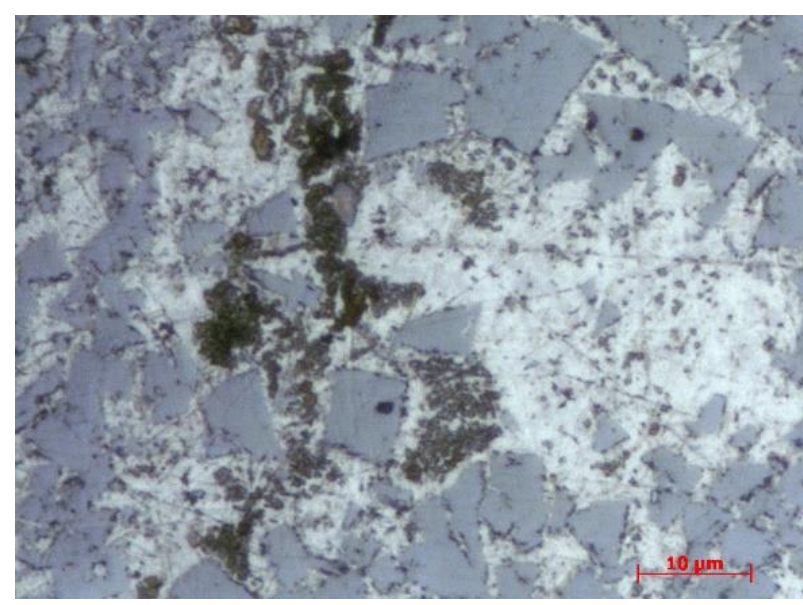

Figure 14. Micrograph of a sintered build from powder mixture B. White areas are cobalt, brown-orange are $\eta$-phase and the grey areas are tungsten carbide WC, magnification 1000×, Murakami etch

The above micrographs illustrate how the powder quality and process parameters impact on the structural composition of the build. In the build from powder mixture A, much of the cobalt binder transformed into brittle $\eta$-phase. The reasons include a large amount of $\eta$-phase in the powder mixture, steep temperature gradients and rapid cooling, during which this phase forms. In the build from powder mixture $B$, the transformation of the binder into $\eta$-phase was less extensive. This is because the input material contained no $\eta$-phase and the powder layer was thicker. As a result, temperature gradients were less steep, hindering the creation of $\eta$-phase. Another factor that contributed to the brittleness of the sintered build was the growth of WC grains. The growth was largest in those locations where Marangoni convection caused clustering. [Gu 2009]; [Kruth 2007] Where the grains touched, they slowly began to coalesce. Due to sufficiently high energy, they also grew while being separate. The mechanical properties of the builds and WC grain sizes are given in Tab. 2 .

\begin{tabular}{|c|c|c|c|}
\hline & $\begin{array}{l}\text { Mean } \\
\text { hardness, } \\
\text { HV1 }\end{array}$ & $\begin{array}{l}\text { Mean WC grain } \\
\text { size prior to } \\
\text { sintering } \\
\text { (powder)/largest } \\
\text { recorded grain } \\
\text { size }(\mu \mathrm{m})\end{array}$ & $\begin{array}{l}\text { Mean WC grain } \\
\text { size after } \\
\text { sintering/largest } \\
\text { recorded grain } \\
\text { size }(\mu \mathrm{m})\end{array}$ \\
\hline $\begin{array}{l}\text { Prototype } \\
\text { build A }\end{array}$ & $1394 \pm 212.1$ & $2.7 \pm 1.2 / 7.8$ & $4.1 \pm 2.66 / 17.1$ \\
\hline $\begin{array}{l}\text { Prototype } \\
\text { build B }\end{array}$ & $871 \pm 197.7$ & $3.56 \pm 1.4 / 6.6$ & $3.7 \pm 2.77 / 16.3$ \\
\hline & \multicolumn{3}{|c|}{ Cohesion/Fragmentability of builds } \\
\hline $\begin{array}{l}\text { Prototype } \\
\text { build A }\end{array}$ & \multicolumn{3}{|c|}{ Poor- Specimens can be crushed by hand } \\
\hline $\begin{array}{l}\text { Prototype } \\
\text { build B }\end{array}$ & \multicolumn{3}{|c|}{$\begin{array}{l}\text { Relatively good-Specimens can only be crushed by a } \\
\text { force applied by a universal tensile testing machine } \\
\text { Maximum compressive strength (approx. } 1200 \mathrm{MPa} \text { ) }\end{array}$} \\
\hline
\end{tabular}

Table 2. Hardness of specimens and their behaviour under mechanical loads.

It follows from these findings that AM processing of WC-Co powder causes WC grains to grow as follows: by approx. $50 \%$ in powder mixture $A$; and approx. $5 \%$ in powder mixture $B$. The variation in the growth of WC grains is a result of their different initial sizes, see Tab. 2. The initiation of WC grain growth in powder mixture $B$ required more energy. Table 2 and Fig. 13 and Fig. 14 also document the structural heterogeneity of the builds, as evidenced by standard deviations of their HV1 hardness. Fig. 13 and Fig. 14 show that the specimens contain Co-rich areas, bright areas like those in Fig. 14, and areas where $W C$ and $\eta$-phase grains formed clusters. This is due to the dynamics of powder sintering during $A M$, where the phase distribution is governed by the scanning speed, the laser spot size and the laser power. These parameters dictate the achievable sintering temperature, the duration of the existence of the melt and the speed of movement of particles through the melt. When the melt exists for a sufficiently long time, segregation of phases may occur in some regions of the build. This is the cause of the heterogeneity of the mechanical properties found in these builds. In this case, the mechanical properties were also affected by high porosity.

\section{CONCLUSION}

The aim of this study was to assess the applicability of two types of WC-Co powder blends for the additive technology known under the abbreviation SLM. The applicability of these blends was assessed on the basis of an analysis of the powder blends and printed samples mainly using light and electron microscopy.

Metallographic analysis of powders A and B showed that the particle shape of powder $A$ was predominantly irregular in contrast to powder mixture $B$, which was predominantly spherical, see figures 1 and 3 .

Analyses of the particle shape and particle size distribution of the powder (see Figure 4) detected surface defects, and the presence of fine powder particles smaller than $1 \mu \mathrm{m}$ affected the flowability of the powder mixtures. Flowability of the powders was measured using two different flow tests. The results of the integrity of the powder layers on the adjusting plate of the additive device were presented, see figures 5 and 6.

From these images it was evident that the layers of powder were not uniform after one crossing of the recoater blade. Therefore multiple crossings of the recoater during the printing 
process were used. Phase analysis of the powder particles also showed differences between the powders. It was shown that powder blend A consisted of three phases: cobalt as binder, tungsten carbide and $\eta$ phase, see Fig 7. Powder B consisted of two phases: cobalt as binder and tungsten carbide, see Fig 8.

This difference was caused by the different way of processing the powder mixtures. Powder A was prepared by sintering and crushing. Powder B was prepared by milling.

Metallographic analysis of the builds showed a volume growth of the $\eta$ phase in the builds made of both powder blends, see figures 13 and 14 .

The presence of $\eta$ phase and volume growth during sintering caused delamination and separation from the build platform, as well as fracturing across the layers. n-phase impaired the mechanical properties of the builds and even precluded their production, particularly at higher energy density levels $\left(E_{v}\right)$. Its distribution depended on the process parameters, namely the laser power and scanning speed. These parameters also altered the distribution of the binder and tungsten carbide within the builds. The mechanical properties and brittleness of builds from both mixtures were affected by WC grain growth and porosity. The number of pores as density of builds was measured by analysing the metallographic images and by direct measurement on the samples where the measured values were compared with those obtained from the conventionally sintered samples. The maximum detected density of builds was about 70 percent, see Fig. 12 . It was not possible to achieve full density of the builds due to the bad distribution of the powder on the building platform and also due to the evaporation of the binder when an excessively high laser power and low scanning speed were used. Porosity of the samples could also be affected by tungsten carbide grain growth, increasing the amount of $\eta$ phase and trapping inert gas or moisture from the powder. [Bricin 2018] Three types of pores were observed in the builds: cracks, pores with open pore structures and pores with closed structures. [Bricin 2018]

Cracks were mainly observed in the builds made of powder $A$, (see Fig 10). This is connected with the increasing amount of $\eta$ phase which caused increased volume stresses in the builds which led to cracking. Closed and open pore structures were mainly observed in the builds made of powder B. Open pore structures were created when the laser power was too low or if the scanning speed was too high. Closed pore structures were created in the opposite case. The existence of closed or open pores was confirmed by cross-sections on each metallographic sample, and a capillary test.

Based on the results of the experiments, it is possible to say that the analysed powders are not acceptable for AM.

However, more advanced WC-Co mixtures are now available on the market which promise better resultant properties. Future experiments will therefore involve these new WC-Co mixtures. The objectives of these studies will be to gain an understanding of the behaviour of these powder mixtures during SLM processing and to design machine parts with unique internal structures that improve their utility properties.

\section{ACKNOWLEDGEMENTS}

Experimental research conducted in this study was supported by grants from the Technology Agency of the Czech Republic as part of the ZETA programme, no. TJ01000218, entitled "Manufacture of carbide cutting tool prototype by SLM additive manufacturing technique" and no. SGS - 2016-036 "Analysis, development and modification of technologies of treatment of bulk advanced materials for power generation machines, transport equipment and related engineering applications". We are also grateful to Mr Michal Ackermann and Mr Jiří Šafka from the Department of Industrial Technology, TU Liberec.

\section{REFERENCES}

[Armstrong 2014] Armstrong, B., Brockbank, K., Clazton, J. (2014). Understand the Effects of Moisture on Powder Behavior. American Institute of Chemical Engineers.

[Bricin 2018] Bricin, D., Spirit, Z. and Kriz, A. (2018). Metallographic Analysis of the Suitability of a WC-Co Powder Blend for Selective Laser Melting Technology.

[Bricin 2018] Bricin, D., Kriz, A. (2018). Comparison of Metallography and Mechanical Properties of Samples Printed from WC-Co Powder Mix Using SLM Technology in Protective Atmospheres of Argon and Nitrogen. Materials, Methods \& Technologies. Volume 12. pp. 326-334.

[Dawes 2015] Dawes, J., Bowerman, R., Trepleton, R. Introduction to the Additive Manufacturing Powder Metallurgy Supply Chain. (2015). Johnson Matthey Technology Review. ISSN 20565135.

[Domashenkov 2016] Domashenkov, A., Borbely, A. and Smurov, I. (2016). Structural modifications of WC/Co nanophased and conventional powders processed by selective laser melting. Materials and Manufacturing Processes, 32(1), pp. 93-100.

[Gu 2009] Gu, D. and Shen, Y. (2009). Balling phenomena in direct laser sintering of stainless steel powder: Metallurgical mechanisms and control methods. Materials \& Design, 30(8), pp. 2903-2910.

[Gu 2015] Gu, D. (2015). Laser Additive Manufacturing of HighPerformance Materials. Springer Berlin Heidelberg. ISBN 978-3662-46088-7.

[Khairallah 2016] Khairallah, S., Anderson, A., Rubenchik, A. and King, W. (2016). Laser powder-bed fusion additive manufacturing: Physics of complex melt flow and formation mechanisms of pores, spatter, and denudation zones. Acta Materialia, 108, pp. 36-45.

[Kruth 2007] Kruth, J., Levy, G., Klocke, F. and Childs, T. (2007). Consolidation phenomena in laser and powder-bed based layered manufacturing. CIRP Annals, 56(2), pp. 730-759.

[Kumar 2009] Kumar, S. (2009). Manufacturing of WC-Co moulds using SLS machine. Journal of Materials Processing Technology, 209(8), pp. 3840-3848.

[Kurzynowski 2012] Kurzynowski, T., Chlebus, E., Kuźnicka, B. and Reiner, J. (2012). Parameters in selective laser melting for processing metallic powders. High Power Laser Materials Processing: Lasers, Beam Delivery, Diagnostics, and Applications.

[Sames 2016] Sames, W., J., List, F., A., Pannala, S., Dehof, R., R., Babu, S., S. (2016). The metallurgy and processing science of metal additive manufacturing. nternational Materials Reviews. ISSN 0950-6608.

[Sarin 2014] Sarin, V. (2014). Comprehensive hard materials. Amsterdam: Elsevier.

[Uhlmann 2018] Uhlmann, E., Bergmann, A. and Gridin, W. (2018). Investigation on Additive Manufacturing of Tungsten Carbide-cobalt by Selective Laser Melting.

[Venuvinod 2004] Venuvinod, P., Weiyin, Ma. (2004) Rapid Prototyping. Springer US. ISBN 978-1-4419-5388-9

[Wang 2002] Wang, X., Laoui, T., Bonse, J., Kruth, J., Lauwers, B. and Froyen, L. (2002). Direct Selective Laser Sintering of Hard Metal Powders: Experimental Study and Simulation. The International Journal of Advanced Manufacturing Technology, 19(5), pp. 351-357. 


\section{CONTACT}

Ing. David Bricin

University of West Bohemia in Pilsen

Faculty of Mechanical Engineering

Univerzitni 22

30614 Plzen

Tel: +420377 638314

e-mail: bricda@kmm.zcu.cz 